Meta

Journal des traducteurs

Translators' Journal

\title{
Team-Teaching Consecutive Interpretation at the Monterey Institute of International Studies
}

\section{Christian Degueldre et Jacolyn Harmer}

Volume 36, numéro 4, décembre 1991

URI : https://id.erudit.org/iderudit/002504ar

DOI : https://doi.org/10.7202/002504ar

Aller au sommaire du numéro

Éditeur(s)

Les Presses de l'Université de Montréal

ISSN

0026-0452 (imprimé)

1492-1421 (numérique)

Découvrir la revue

\section{Citer cette note}

Degueldre, C. \& Harmer, J. (1991). Team-Teaching Consecutive Interpretation at the Monterey Institute of International Studies. Meta, 36(4), 684-687.

https://doi.org/10.7202/002504ar
Résumé de l'article

On présente une expérience d'enseignement en équipes effectuée avec des étudiants de première année en interprétation consécutive (français/anglais). On explique pourquoi on a choisi cette méthode d'enseignement, comment les cours ont été menés et enfin on donne les résultats obtenus. 


\section{TEAM-TEACHING CONSECUTIVE INTERPRETATION AT THE MONTEREY INSTITUTE OF INTERNATIONAL STUDIES*}

\author{
Résumé
}

On présente une expérience d'enseignement en équipes effectuée avec des étudiants de première année en interprétation consécutive (français / anglais). On explique pourquoi on a choisi cette méthode d'enseignement, comment les cours ont été menés et enfin on donne les résultats obtenus.

An effective teacher of interpretation must first and foremost believe in what he or she does - then, he must know, comprehend, appreciate, what it is he does: surely the best way of satisfying these two imperatives is for the teacher to be active in both professions - not consecutively but simultaneously, - if you will pardon the pun - whereby the teacher IS an interpreter.

Although this seems a sound premise, I must immediately qualify it: I must concede that there are those who teach interpretation and are the exception to the rule - I am sure we may all have someone in mind who brings inspiration and talent to the classroom but is not a practicing conference interpreter.

Similarly, it is equally true that the very best interpreter, outstanding in his field, competent, quickwitted and conscientious, when asked to teach a class of student interpreters, may well turn out to be a square peg in a round (pedagogical) hole - with all the discomfort that the metaphor suggests! In such circumstances, the teacher, the students' mentor and model, may at the very least fail to communicate his passion to students, or worse, may wind up dominating the class by imposing a reign of terror.

We have spoken of the two hats that the teacher of interpretation ideally wears. (Those of pedagogue and professional). As if that were not enough, ideally he should sport a third - the mortar board, or the hat associated with the scholar. New research and writing in the field may inspire more effective teaching strategies, as colleagues, who otherwise have the chance to meet all too rarely, (or in unpropitious circumstances)... share their experiences. The main purpose of our presentation today is to review our experience of team-teaching consecutive interpretation, French/English, to a class of first-year students.

Why did we decide to team-teach?

How did we conduct classes?

What were the results?

Our teaching schedule in Monterey had "paired" us to teach consecutive interpretation, as native speakers of French and English. In other words, we would alternate with each class and shift emphasis as appropriate. As we met to confer on students' progress - and on our own progress with the same group of students - it was soon obvious that we were seeing the same patterns and problems.

Pooling resources, we felt, would create a more inspiring - and realistic - classroom environment. We believed that the whole would be greater than the sum of the parts - we hoped that, by working as a team, we would add a dimension to the students' training.

Since then, we have tried team-teaching in different contexts; in other words, in simulated negotiations and in simultaneous interpretation classes and with other language combinations and colleagues too. Today, however, our paper focusses on one experience in particular.

Our classes now consolidated, we met with the students once a week for three hours. A workshop 
off-campus was planned towards the end of the semester.

Teaching consecutive interpretation in the classroom proved to be a question of balance in many respects - between the stress inherent to the task and the demands of the task itself, for example, or, a balance between constructing an exercise in class and defining the quality of the performance expected of the professional interpreter.

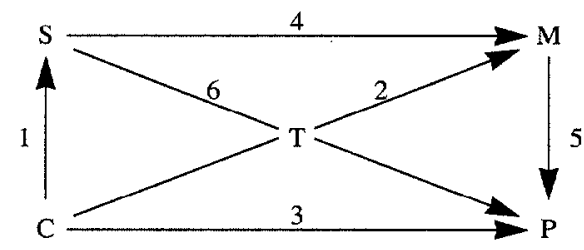

1. The class is taught gradually how to handle stress.

2. Accuracy must be a priority.

3. The student's approach to interpretation must reflect the context in the "real" world.

4. Mishandled stress impedes comprehension and faithful rendering of the message.

5. As an eminent colleague put it so well "interpréter, c'est d'abord comprendre": this is reminiscent of the delegate who says in all seriousness: "I don't need an interpretation just tell me what he is saying..."

6. Stress is intrinsic to the profession.

We could feel the enthusiasm and commitment to the task that new students brought with them into the classroom. However, as soon as they were asked to take a risk for the first time, by making a speech, or recounting the content of a short presentation, adrenalin levels hit the ceiling. We were careful, therefore, not to attempt too much too quickly. Over the semester, however, our approach to teaching consecutive interpretation nevertheless emerged as being an integrated exercise.

First things first...

We defined our goals from a number of different perspectives. Perhaps the most effective tool for this purpose proved to be the demonstration. Not many students had first-hand experience of seeing a professional interpreter at work - (although most had seen our colleagues accompanying Messrs. Bush and Gorbachev on the T.V. News).

At the beginning of the semester, faculty combine forces to demonstrate consecutive and simultaneous interpretation, as well as sight translation. Following each demonstration, (the consecutive is done with the help of an overhead projector), students have an opportunity to ask questions. Professional presentation and note-taking technique are perhaps the two things that strike them most. This is our first chance to reassure students that it is not all done by telepathic communication or by mirrors, and that, with aptitude and application, the skills employed by the conference interpreter are not beyond reach.

In the first class, we sketch out what is expected by the end of the first year. Again demonstrations help, as later in the semester, second year students offer to provide "demos" for the first year - (although "offer" is stretching the truth a little...). The obvious benefit of the exercise is that first years are able to see what they can achieve in a year. The less obvious benefit is that the exercise usually boosts the confidence of the more advanced students, as they are cast in the role of expert, albeit with some way still to go. Beginners always ask their new role models at what point they felt they were approaching their goal.

The other question beginners ask is why it is necessary to learn consecutive at all. This partly stems from the students' fear of exposure which does not seem to loom as large in the case of simultaneous interpretation.

Our response to this question is both academic and practical. Academic, as we concur that consecutive skills are the cornerstone of interpreter training, that watching the beginner at work is akin to peeping through a window into the mind; practical, because most employers prefer to test consecutive interpretation first (in some cases, it is even eliminatory) and quite simply because it is used in the profession.

In class we attempt to impart the skills of consecutive interpretation to students by what we shall call "modelling" (two different models) and by introducing the following skills in sequential/integrated fashion:

- active listening

- concentration

- stress management and positive reinforcement

- discourse analysis

- perception of structure

- attention splitting

- anticipation

- presentation

note-taking

\section{STRESS}

Talking to students and observing their performance, we can readily identify different sources of stress:

- US, (the teachers) for example!

- apprehension because of lack of experience

- fear of not being able to understand

- phobia of not being understood

- terror of inadequate memory

- anxiety about being wrong

a trepidation of not being able to find the "right word"

- dread of speaking in public

horror of judgement of peers. 
The presence of the Teacher (in our case, a double dose) is a doubtless source of tension. Consequently, we tried to create a working partnership with students in a bid to break through the student/ teacher barrier. We hoped to convince students that their focus should be satisfactory performance rather than passing an exam.

Learning, we emphasized, was better served by cooperation with one another rather than by competition. Mutual critique can be a mine-field we saw how important it would be to advise students how to criticize one another in a constructive rather than destructive way. In his book Zen and the Art of Motorcycle Maintenance, Mr. Pirsig tells how he experimented with ways of teaching students to recognize QUALITY - a subject indeed worthy of a week's retreat in a quiet place! We hold that, as quality is ultimately defined subjectively, so the beginner interpreter gradually learns "to know" what is good and what is not.

From the first class, we set a working context expecting students to be prepared, punctual and in the right frame of mind. Active listening is then our first priority, illustrated by a demonstration of passive (poor) listening. This demonstration seems quite comical, but the lesson is far from being trivial - in each of our everyday lives, a conversation partner who will give us full attention without interruption, contradiction or liberally dispensing unsolicited advice is a rare and precious find. This same quality is surely essential in the conference interpreter.

Extemporaneous speeches on familiar topics provide the content for classwork at first. Improvised material by its nature, with its hesitations, relative simplicity and openness, has proven its worth with beginners. Subjects are drawn from current affairs and the news, so that all students are (ideally) equally prepared. These short presentations are 'interpreted' from $\mathrm{A}-\mathrm{A}$ - and later $\mathrm{B}-\mathrm{A}$ and $\mathrm{A}-\mathrm{B}$ - to develop active listening skills and to persuade students that they all have a fine memory, although many until now simply have not been managing it properly.

We encourage students not to be afraid of being wrong, - which does not mean that we encourage them to be wrong, but we show them during the course of their training that when they make a mistake, it is more important for the interpreter to identify it and correct it quickly and efficiently, instead of plunging into the abyss of despair because she or he has not interpreted to perfection.

These are some of the ways we try to dispel stress during the class. For those still contending poorly with stress, a workshop is offered on campus in the spring.

\section{MEANING}

We next build upon active listening skills, still asking students to interpret extemporaneous speeches, in order to instill confidence in each student that she or he can remember.

The consecutive interpreter's most valuable tool is a medium-term memory, or, in Prof. Seleskovitch's terms, a cognitive memory. This means an ability to recall which is anchored on analysis of discourse that is, content - and structure - or form - as meaning is divided into content and form.

After a short speech, students should know what has been said, why it was said and how. Furthermore, the structure of the discourse should have been perceived - or the student called upon to interpret must "impose" one.

Every utterance should be scrutinized in its context: everything the interpreter hears is appraised and checked for logic. Identifying with the speaker, the interpreter can begin to anticipate the flow of discourse more easily.

To provide an exercise in anticipation, the speaker may role-play, announcing his topic and his identity. The interpreters then pool their own knowledge of the topic and vocabulary in the target language, and try to predict what the speaker will say. Whilst team-teaching, we habitually play the role of obtuse monolingual delegate, requiring students to interpret our commentary as well as our speeches.

Note-taking is still conspicuously absent. All are still learning to trust their cognitive memory. We practice more efficient ways of remembering things, e.g. visually in particular, or auditorily, by association, by structure.

Memory exercises include speeches that describe processes, jokes and anecdotes - ideally speeches which allow for visualization - or which beg it where possible. We borrow from Katarina Reiß' (Würzburg/Germersheim) invaluable theories initially applicable to translation as surveyed in her article in Lebende Sprachen, (1984): "Methodische Fragen der Übersetzungsrelevanten Textanalyse".

Her paper suggests that the translator for our purposes read: interpreter) should have a quiver full of arrows in the form of questions ready to fire at the speech: Roughly, who is saying what to whom, how and why and to what effect, when and where, and what is it that the speaker is not telling us? In our case we add: Is the speaker contradicting himself by his expression or body-language?

Whilst not dwelling on the importance of discourse analysis here, it is clear that it underlies the entire process; remember: "interpréter, c'est d'abord comprendre",

All this time, it is primarily the students themselves giving speeches, according to certain guidelines. In preparing speeches themselves, they soon become aware of structure - and conversely, absence thereof. They also soon hear from their peers how hard it is to interpret a speech which is structured weakly or illogically - not to mention where the content is inaccurate, when it is read from a printed source, or is laced with meaning errors... 


\section{NOTE-TAKING}

In the first stages of note-taking, students may "draw" the structure of a short speech, using arrows, lines and a minimum of symbols only. Note-taking must be introduced only when students are ready and then with a great deal of caution.

\section{CLASSROOM AND PROFESSIONAL PERFORMANCE}

Dare we return to the metaphor of balance once more?

In conclusion, we decided to combine these factors (classroom and professional performance) since they are interrelated and from the very beginning of training must be approached together. Our work in the classroom is aimed at guiding students toward what is needed in the profession (we simulated the conference room environment in the classroom). Since we know the profession well, we can ensure that students' grades and their degree are no longer the overriding factors, but rather relevant preparation for the profession.

\section{FORM}

We then begin to add form. Presentation now takes on more importance, because it is by modulating the voice and maintaining eye-contact with the audience that the professional interpreter retains the attention - and trust - of the listeners.

In order to propel students gently into the professional world, we eventually leave the classroom altogether and arrange a field trip, the first in a series of opportunities for the students to practice their new skills in public.

Although it was planned that way, we offered two (complementary we believe...) different models. We naturally converged on different aspects of consecutive interpretation in our feedback. Consequently, students were not restricted to modelling one style only.

What we have told you is about as far as we can go - the rest is practice, practice and more practice...

\section{RESULTS}

In spite of some parameters that proved beyond our control (inadequate aptitude or language proficiency, personality conflicts, unrealistic expectations) we believe that team-teaching was a much more lively way to teach; the students' own evaluations indicated that they got a lot more out of it.

We cannot lay down any hard and fast rules for team-teaching because every set of circumstances is different: different students, different cultures and different personalities among the faculty.
It is an approach to teaching consecutive interpretation that we certainly plan to repeat, as both students and teachers alike were pleased with the results.

* Abbreviated version of an oral presentation on the Training of Teachers of Translation and Interpretation, at the 1989 Twentieth Anniversary Symposium, Monterey Institute of International Studies.

\section{CHRISTIAN DEGUELDRE AND} JACOLYN HARMER Monterey, USA 